\title{
A defect in dystrophin causes a novel porcine stress syndrome
}

\author{
Dan J Nonneman*, Tami Brown-Brandl, Shuna A Jones, Ralph T Wiedmann and Gary A Rohrer
}

\begin{abstract}
Background: Losses of slaughter-weight pigs due to transport stress are both welfare and economic concerns to pork producers. Historically, the HAL-1843 mutation in ryanodine receptor 1 was considered responsible for most of the losses; however, DNA testing has effectively eliminated this mutation from commercial herds. We identified two sibling barrows in the USMARC swine herd that died from apparent symptoms of a stress syndrome after transport at 12 weeks of age. The symptoms included open-mouth breathing, skin discoloration, vocalization and loss of mobility.

Results: We repeated the original mating along with sire-daughter matings to produce additional offspring. At 8 weeks of age, heart rate and electrocardiographs (ECG) were monitored during isoflurane anesthesia challenge ( $3 \%$ for $3 \mathrm{~min}$ ). Four males from the original sire-dam mating and two males from a sire-daughter mating died after one minute of anesthesia. Animals from additional litters were identified as having a stress response, sometimes resulting in death, during regular processing and weighing. Affected animals had elevated plasma creatine phosphokinase (CPK) levels before and immediately after isoflurane challenge and cardiac arrhythmias. A pedigree containing 250 pigs, including 49 affected animals, was genotyped with the Illumina PorcineSNP60 Beadchip and only one chromosomal region, SSCX at 25.1-27.7 Mb over the dystrophin gene (DMD), was significantly associated with the syndrome. An arginine to tryptophan (R1958W) polymorphism in exon 41 of DMD was the most significant marker associated with stress susceptibility. Immunoblots of affected heart and skeletal muscle showed a dramatic reduction of dystrophin protein and histopathology of affected hearts indicated muscle fiber degeneration.

Conclusions: A novel stress syndrome was characterized in pigs and the causative genetic factor most likely resides within DMD that results in less dystrophin protein and cardiac abnormalities that can lead to death under stressful conditions. The identification of predictive markers will allow us to determine the prevalence of this disease in commercial swine populations. This defect also provides a unique biomedical model for human cardiomyopathy associated with muscular dystrophy that may be superior to those available because of the similarities in anatomy and physiology and allow advances in gene therapies for human disease.
\end{abstract}

\section{Background}

Losses of market-weight pigs present economic, legal and animal welfare issues to U.S. swine producers and include dead, non-ambulatory, fatigued and injured pigs [1]. Although the incidence occurs at low frequency (less than 1\%) these losses are substantial due to added labor and disposal costs, along with loss of full-value product and have been estimated to be over $\$ 50,000,000$ per year in the U.S. Fatigued, non-ambulatory pigs exhibit acute stress symptoms including open-mouth breathing,

\footnotetext{
* Correspondence: dan.nonneman@ars.usda.gov

USDA, ARS, U.S. Meat Animal Research Center, Clay Center, Nebraska, USA
}

discoloration (red to purple) and blotching of skin, muscle tremors, abnormal vocalization and refusal to move, similar to what is observed in pigs with malignant hyperthermia due to a mutation in the ryanodine receptor 1 gene (RYR1) [2]. A DNA-based test has been available since the discovery of the mutation and producers have been able eliminate the unfavorable RYR1 allele from their herds [3]. Over a decade ago it was found that half of the pigs arriving dead or dying at the packing plants carried at least one copy of the RYR1 mutation [4]. By 2006 the number of dead and non-ambulatory pigs that carried the RYR1 mutation was about 5\% [3];

\section{Biomed Central}

(c) Nonneman et al.; licensee BioMed Central Ltd. This is an Open Access article distributed under the terms of the Creative Commons Attribution License (http://creativecommons.org/licenses/by/2.0), which permits unrestricted use, distribution, and reproduction in any medium, provided the original work is properly cited. 
thus, the mutation was still present at a low frequency at that time [3]. However, a high proportion of RYR1 normal pigs show a sensitivity to halothane anesthesia [5] and are more prone to becoming non-ambulatory after handling [6]. Pigs that are more sensitive to halothane exposure may also have inferior pork quality [5]. These relationships are believed to have a genetic basis; however, the specific cause has yet to be identified.

In the U.S. Meat Animal Research Center's swine research population, a novel stress syndrome was detected. Test matings were made to characterize the syndrome's physiological effects and its genetic basis. This study reports the identification of a novel porcine stress syndrome and mapping of the defect to dystrophin.

\section{Results}

Identification and challenge of stress susceptible pigs

The original mating that produced pigs that died after transport was repeated. Five males were born and three were classified as affected when they died after administration of isoflurane anesthesia. Because isoflurane challenge seemed to elicit a stress response, this treatment was used to test pigs from subsequent suspect litters. A total of 242 piglets from 32 litters (21 sows and 13 boars) were challenged with isoflurane anesthesia and we obtained at least one plasma creatine phosphokinase (CPK) measurement for 192 pigs, before or after anesthesia challenge. Pigs were classified as being affected if they died during handling, transport or isoflurane challenge or had high CPK levels and an abnormal ECG (Figure 1). Heart rates of unaffected pigs remained steady throughout anesthesia challenge. The average CPK levels were more than three times higher in
Table 1 Plasma creatine phosphokinase activity in normal and stress-responsive pigs

\begin{tabular}{lccc}
\hline Group $^{\mathbf{a}}$ & Normal $(\mathbf{n}=\mathbf{1 0 3}){ }^{\mathbf{b}}$ & Carrier $(\mathbf{n}=\mathbf{3 7})$ & Affected $(\mathbf{n}=\mathbf{3 5})^{\mathbf{c}}$ \\
\hline Pre-challenge & $482.42 \pm 41.30$ & $573.93 \pm 89.14$ & $1635.27 \pm 148.22$ \\
Post-challenge & $644.37 \pm 68.80$ & $469.26 \pm 51.08$ & $1928.46 \pm 136.37$ \\
\hline
\end{tabular}

${ }^{a}$ Pre-challenge was at 7 weeks of age, post-challenge was at 8 weeks of age after isoflurane treatment.

${ }^{b}$ Mean and standard error of plasma CPK in units/liter. Of 192 pigs that were sampled, not all the normal animals were challenged with isoflurane anesthesia.

' Values were not different before or after challenge; affected pigs had significantly greater CPK activity than normal or carrier pigs $(p<0.0001)$.

affected pigs compared to their unaffected littermates both before and after isoflurane challenge $(p<0.0001$, Table 1). Females that were later confirmed to be carriers, based on genotype and progeny testing, had CPK levels that were not different from unaffected animals before or after isoflurane challenge (Table 1). Isoflurane treatment itself did not affect CPK levels. Of the fortynine presumed affected pigs, based on isoflurane response, CPK levels or assessment of their ECG, only 18 died during anesthesia. These animals showed signs of respiratory distress and a rapid decline in heart rate usually within one minute of anesthesia. Eight affected animals died a few days after challenge while being transported.

\section{Mapping the stress syndrome locus}

To identify the genomic region associated with the stress syndrome, the coding regions of porcine orthologs of human malignant hyperthermia $(\mathrm{MH})$ genes $R Y R 1$, CACNA1S, CPT2 and RYR2 were sequenced for SNP discovery in the proband's family (Additional file 1: Table
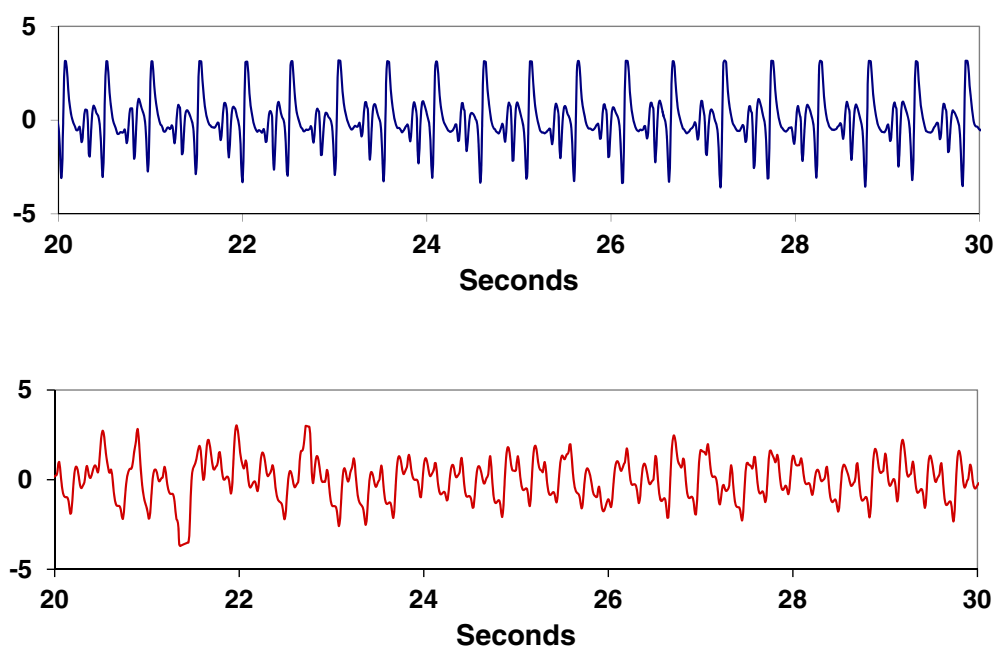

Figure 1 Electrocardiograms of normal and affected littermates. Eight week-old normal (top) and affected (bottom) littermates pigs were challenged with $3 \%$ isoflurane anesthesia and heart rates were monitored for 3 minutes. The electrocardiograms are showing traces from 20 to 30 seconds after administration of anesthesia. 
S1). No obvious mutations were identified comparing normal and affected siblings and the syndrome did not segregate with SNP alleles in any of the human candidate genes. A larger pedigree of 250 pigs, including 49 affected animals was then genotyped with the Illumina PorcineSNP60 Beadchip. Genotypes were called for 59,895 SNPs spanning the entire porcine genome and 49,006 of these could be mapped to build 9.2 (SGSC Sscrofa9.2/susSCR2) of the pig genome. Genome-wide association analysis was done using the case/control association option of PLINK [7]. Only one chromosomal region had highly significant SNP associations, six of which were located between 25.13 and $27.72 \mathrm{Mb}$ on the $\mathrm{X}$ chromosome (Figure 2). When only the 28 animals that died during transport or isoflurane challenge were classified as affected in the analysis, a similar but less significant association was found with the same markers at the dystrophin locus $\left(\mathrm{p}<2 \times 10^{-11}\right)$. The two most significant SNPs on the beadchip (ALGA0099513 and ALGA0099514) are located within intron 44 of the dystrophin gene $(D M D)$. All of the affected animals were hemizygous or homozygous for a shared haplotype.

\section{Sequencing of the porcine dystrophin gene}

The exons and flanking intron sequences of $D M D$ were obtained from normal and affected pigs by PCR amplification and direct sequencing. No polymorphisms were identified near splice sites. The cDNA from normal and affected animals was also amplified and sequenced and there was no evidence of alternative splicing or deletion of exons in the affected animals. The promoter regions P1, P2 and the muscle-specific promoter were sequenced and no obvious mutations were found. Forty-seven SNPs were found in $D M D$ by sequencing 12 members of the affected family; of these, five non-synonymous polymorphisms were found in the coding region (Additional file 2: Table S2). One SNP in particular, 85890_783, that causes the amino acid change arginine to tryptophan at amino acid 1958 (R1958W) in exon 41 was predicted by PolyPhen-2 [8] (http://genetics.bwh.harvard.edu/pph2/) to be damaging with a probability score of 0.983 .

\section{Association of dystrophin SNPs with porcine stress syndrome}

The SNPs in the dystrophin gene identified by sequencing were genotyped across the same pedigree and analyzed for association. The 85890_783 SNP (R1958W) was as highly associated with the stress response as the two most significant SNPs on the Illumina Beadchip (Table 2). The $\mathrm{C}$ allele (arginine) was found in all unaffected animals and the $\mathrm{T}$ allele (tryptophan) was found in affected and carrier females. A survey of 122 presumably unaffected 2008-born barrows from 24 sires and 76 dams all carried the $\mathrm{C}$ allele. The founding ancestors of this population were genotyped for the 85890_783 SNP and five of 12 Landrace boars carried the $\mathrm{T}$ allele, while all 12 of the Duroc boars carried the C allele. Of 122 of the founding dams (Landrace-Yorkshire composite) that were genotyped, two were homozygous and four were heterozygous for the $\mathrm{T}$ allele. In a panel of 192 unrelated boars of different breeds [9], the T allele was only found in 5 of 43 Landrace and 3 of 29 Hampshire boars.

Linkage disequilibrium $\left(\mathrm{r}^{2}\right)$ was estimated for the SNP using Haploview 4.0 software [10] (http://www.broad.

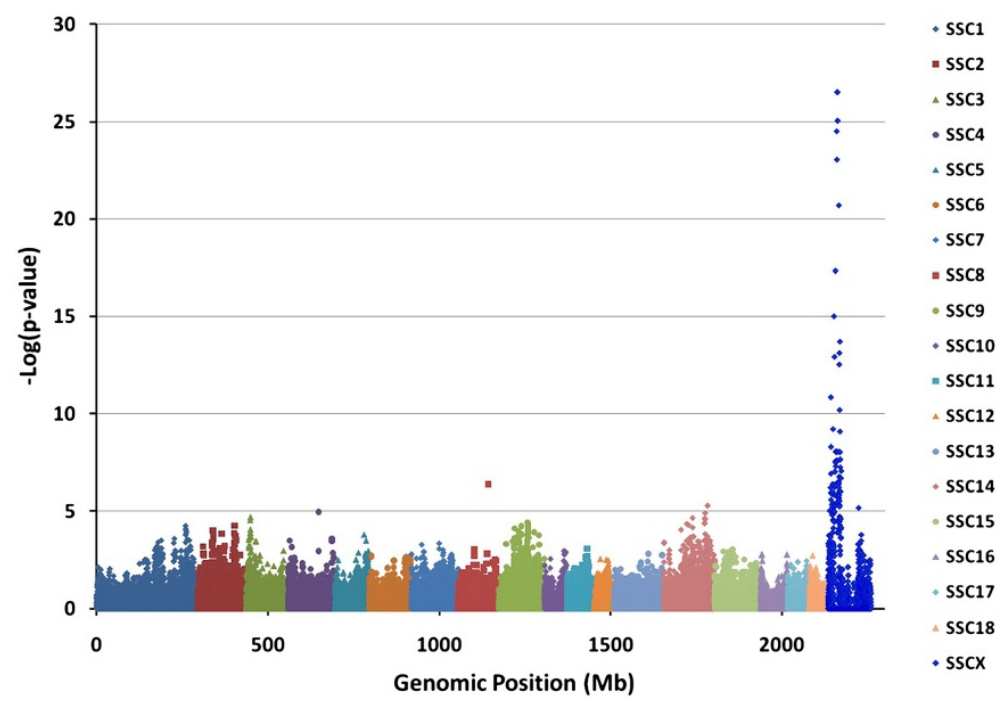

Figure 2 Genome-wide case/control association for stress response in pigs. The cumulative position in the genome (Mb) on the $X$-axis is plotted against the $-\log _{10}(\mathrm{p}$-value) for SNP associations on the Y-axis. The Bonferroni correction for genome-wide significance is a - Log $10(\mathrm{p}$ value) of 6 . The single most significant SNP associations are on the $X$ chromosome. 
Table 2 Associations of SNP in dystrophin with the stress response

\begin{tabular}{|c|c|c|c|c|c|c|c|c|}
\hline SNP & dbSNP\# & Basepair $^{a}$ & $A 1^{b}$ & F_A $A^{c}$ & F_U & A2 & P-value & $-\log (p)$ \\
\hline 84116_121 & ss410758942 & 26546329 & A & 0 & 0.1977 & G & 0.000245 & 3.6117 \\
\hline 84102_437 & ss410758941 & 26635210 & $\mathrm{~T}$ & 0 & 0.1837 & C & 0.001723 & 2.7637 \\
\hline 85904_613 & ss410758951 & 27322071 & $\mathrm{~T}$ & 0.03509 & 0.1886 & C & 0.004925 & 2.3076 \\
\hline 85890_783 & ss410758971 & 28023949 & C & 0 & 0.7485 & T & $1.06 \mathrm{E}-23$ & 22.9759 \\
\hline ALGA0099514 & rs80929421 & 27689253 & C & 0 & 0.7401 & T & $2.19 \mathrm{E}-23$ & 22.6605 \\
\hline ALGA0099513 & rs80914436 & 27716318 & C & 0 & 0.7401 & T & $2.19 \mathrm{E}-23$ & 22.6605 \\
\hline 85896_775 & ss410758960 & 27762149 & T & 0 & 0.1579 & A & 0.001687 & 2.7729 \\
\hline 84024_171 & ss410758936 & 27786935 & C & 0 & 0.1598 & A & 0.00143 & 2.8447 \\
\hline 85894_336 & ss410758939 & 27840323 & A & 0 & 0.4971 & C & $1.28 \mathrm{E}-11$ & 10.8935 \\
\hline 84339_200 & ss410758953 & 27922373 & G & 0 & 0.01163 & A & 0.4055 & 0.3920 \\
\hline 84008_345 & ss410758980 & 27922512 & A & 0 & 0.1579 & G & 0.001535 & 2.8139 \\
\hline 84339_333 & ss410758954 & 27934448 & A & 0 & 0.005848 & G & 0.5594 & 0.2523 \\
\hline 84002_411 & ss410758948 & 27942562 & C & 0 & 0.2059 & G & 0.000195 & 3.7091 \\
\hline 84000_82 & ss410758968 & 28119423 & G & 0 & 0.1471 & A & 0.001967 & 2.7062 \\
\hline 85413_679 & ss410758963 & 28465839 & C & 0 & 0.02013 & T & 0.2848 & 0.5455 \\
\hline 85413_571 & ss410758964 & 28465948 & A & 0 & 0.00578 & G & 0.5617 & 0.2505 \\
\hline 85404_372 & ss410758935 & 28517880 & - & 0 & 0.2073 & A & 0.000239 & 3.6220 \\
\hline
\end{tabular}

${ }^{\mathrm{a}}$ Map position is based on SGSC Sscrofa build 9.2.

${ }^{\mathrm{b}} \mathrm{A} 1$ and $\mathrm{A} 2$ represent the different alleles.

${ }^{\mathrm{C}} \mathrm{F} \_\mathrm{A}$ is the frequency of allele 1 in cases and $F_{-} \mathrm{U}$ is the frequency of $\mathrm{A} 1$ in unaffected.

mit.edu/mpg/haploview/index.php) with the haplotype blocks based on pair-wise LD values. The calculated $r^{2}$ values for SNP 85890_783 and the two most significant SNPs on the beadchip (ALGA0099513 and ALGA0099514) were 0.81 (Figure 3) using the entire pedigree that contained the extended stress family and six other unrelated affected families. Including all founder animals, 122 barrows and 192 unrelated boars that had been genotyped for these three markers, the $\mathrm{r}^{2}$ value was 0.64 between SNP 85890_783 and

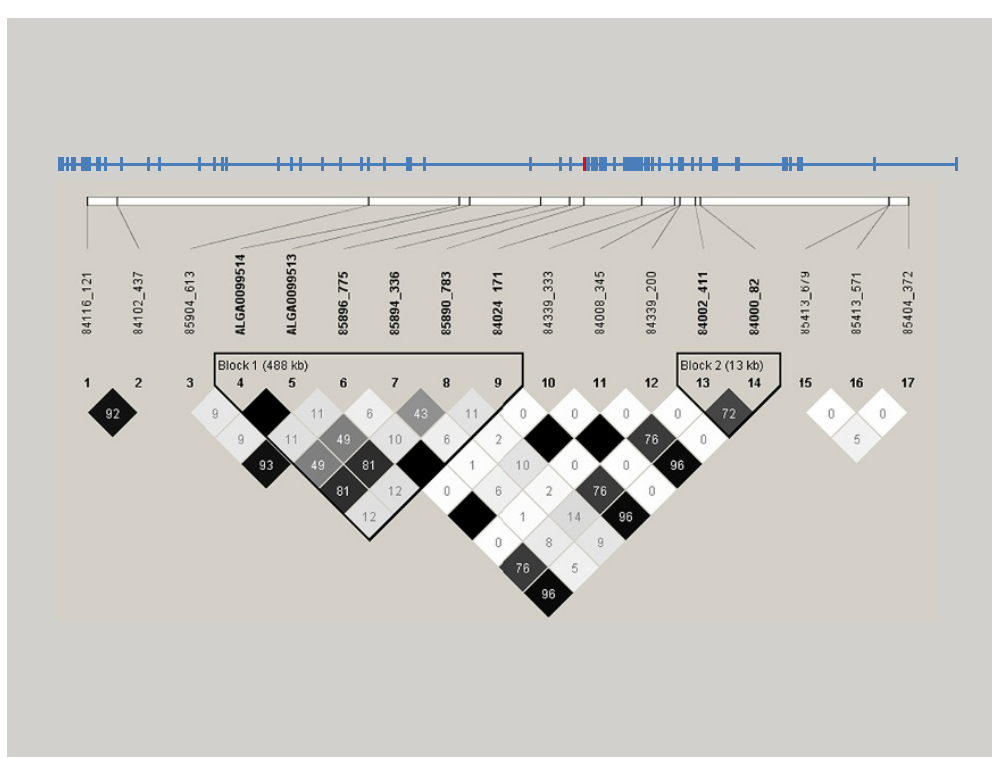

Figure 3 Linkage disequilbrium plot of SNPs in the dystrophin gene in the stress family $(\mathbf{n}=\mathbf{2 5 0})$. The exon organization is shown above the plot, as well as the relative position of SNPs in the DMD gene. The most significant SNPs on the PorcineSNP60 beadchip (ALGA0099514 and ALGA0099513) are in complete LD with each other. The most significant SNP in the DMD gene (85890_783; marker number 8) is located in exon 41 (shown in red above). 
ALGA0099513 and ALGA0099514. The two markers on the beadchip (ALGA0099513 and ALGA0099514) were in complete linkage disequilibrium in both populations (Figure 3).

\section{Evaluation of cardiac and skeletal muscle for the dystrophin defect}

Histopathology of affected left ventricular cardiac tissues showed evidence of myofibrillar degeneration and necrosis (Figure 4). Myocardial fibers showed loss of crossstriation, pyknotic nuclei and associated aggregation of lymphocytes. Immunoblots of heart and skeletal muscle protein from 8 week-old pigs using MANDYS8, a mouse monoclonal anti-dystrophin antibody that recognizes residues 1431-1505 in spectrin repeat regions 10 and 11 of human dystrophin, showed a dramatic reduction $(\sim 50 \%)$ in dystrophin protein in affected pigs compared to normal littermates (Figure 5). Similarly, immunoblots of heart total protein from 6 month-old pigs using

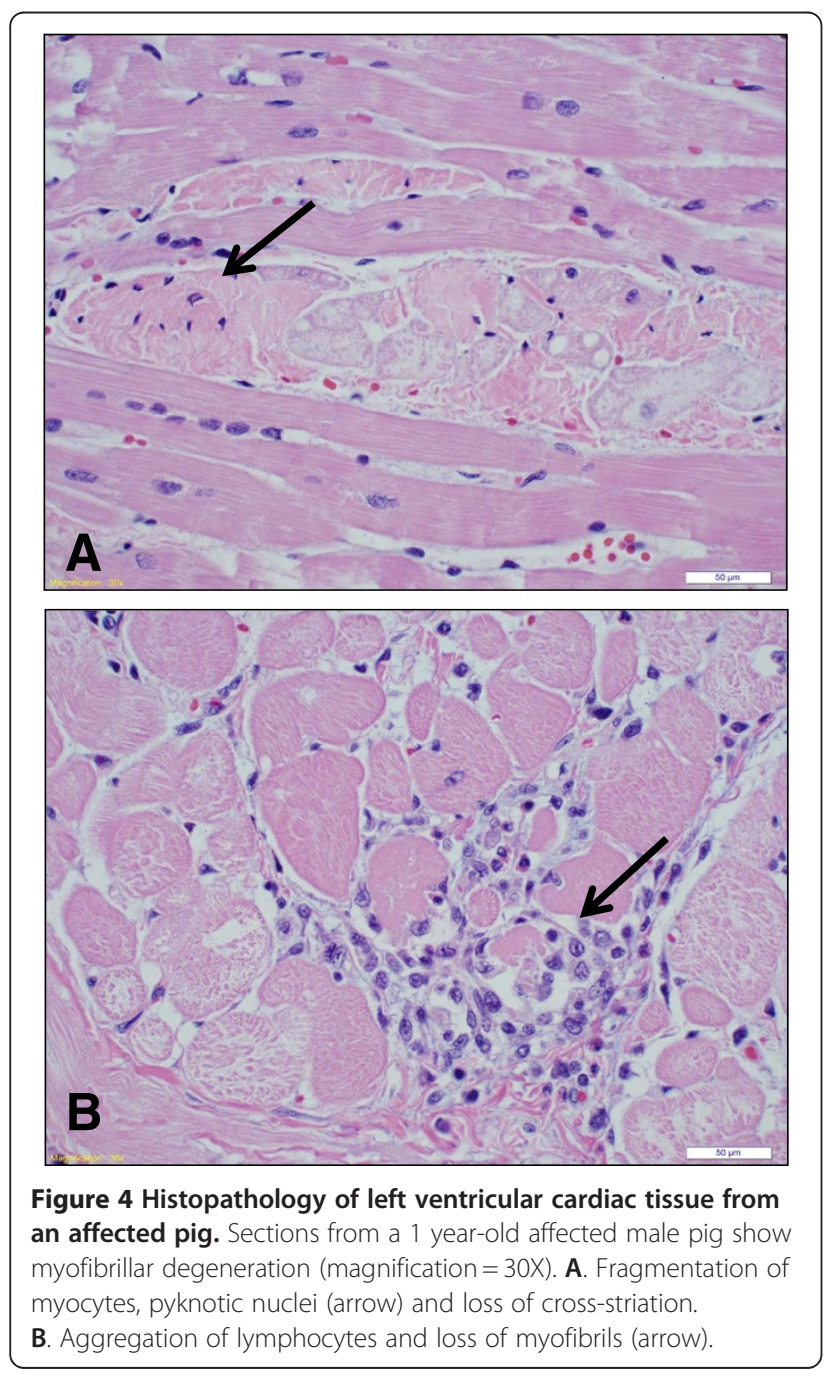

MANDRA1, a mouse monoclonal anti-dystrophin antibody that recognizes residues $3667-3671$ in the C-terminus of the human protein, showed a similar reduction in the amount of protein, as well (Figure 6). Real-time qPCR of dystrophin in 12 affected and 12 unaffected heart tissues using primers in exons 4 and 6 showed no difference in dystrophin mRNA abundance $(1.22 \pm 0.313$ vs. $1.42 \pm 0.34$ fold, $\mathrm{p}=0.677$, respectively).

\section{Discussion}

We have identified a porcine stress syndrome that can be induced by transport, handling or isoflurane anesthesia. Affected animals quickly become non-ambulatory, have difficulty breathing and rarely recover. Isoflurane anesthesia was tested to elicit a stress response because we thought the stress syndrome was a malignant hyperthermia, similar to the classic porcine stress syndrome. Isoflurane is more readily available, less irritating to the respiratory system and has replaced halothane as a common anesthesia for veterinary applications. Although the response is delayed, compared to halothane, isoflurane can also induce malignant hyperthermia in swine [11]. Using the Illumina PorcineSNP60 Beadchip we were able to map the defect to dystrophin on the $\mathrm{X}$ chromosome and show that affected animals have reduced dystrophin protein in heart and skeletal muscle and elevated CPK levels in blood. These animals, however, have no apparent muscle impairment later in life. Dystrophin is the largest gene in the mammalian genome covering 2.4 megabases of DNA, and contains 79 exons and multiple tissue-specific promoters and transcripts [12]. Mutations in dystrophin cause Duchennes Muscular Dystrophy (DMD), Becker Muscular Dystrophy (BMD) and Xlinked dilated cardiomyopathy (XLCM) in humans [12]. Most cases of DMD or BMD involve deletions/duplications, followed by nonsense mutations and/or microdeletions/insertions, most of which cause a frameshift or exon skipping; missense mutations are extremely rare [13-16]. DMD is usually caused by deletions, duplications or nonsense mutations that disrupt or truncate the reading frame, while BMD mutations usually preserve the reading frame $[13,15]$. These allelic forms are generally characterized by the severity and age of onset of the disease with DMD manifesting within the first few years of life as a progressive weakness and wasting of muscle, while BMD occurs in later decades and is more variable in severity. Patients with either DMD or BMD usually develop dilated cardiomyopathy independent of the degree of skeletal muscle involvement [17] and usually have higher than normal circulating levels of CPK $[15,18]$. Likewise, patients with XLCM $[19,20]$, also have elevated $\mathrm{CPK}$, probably due to increased membrane permeability [21], because the absence of dystrophin makes the membrane more susceptible to tears under the force of 


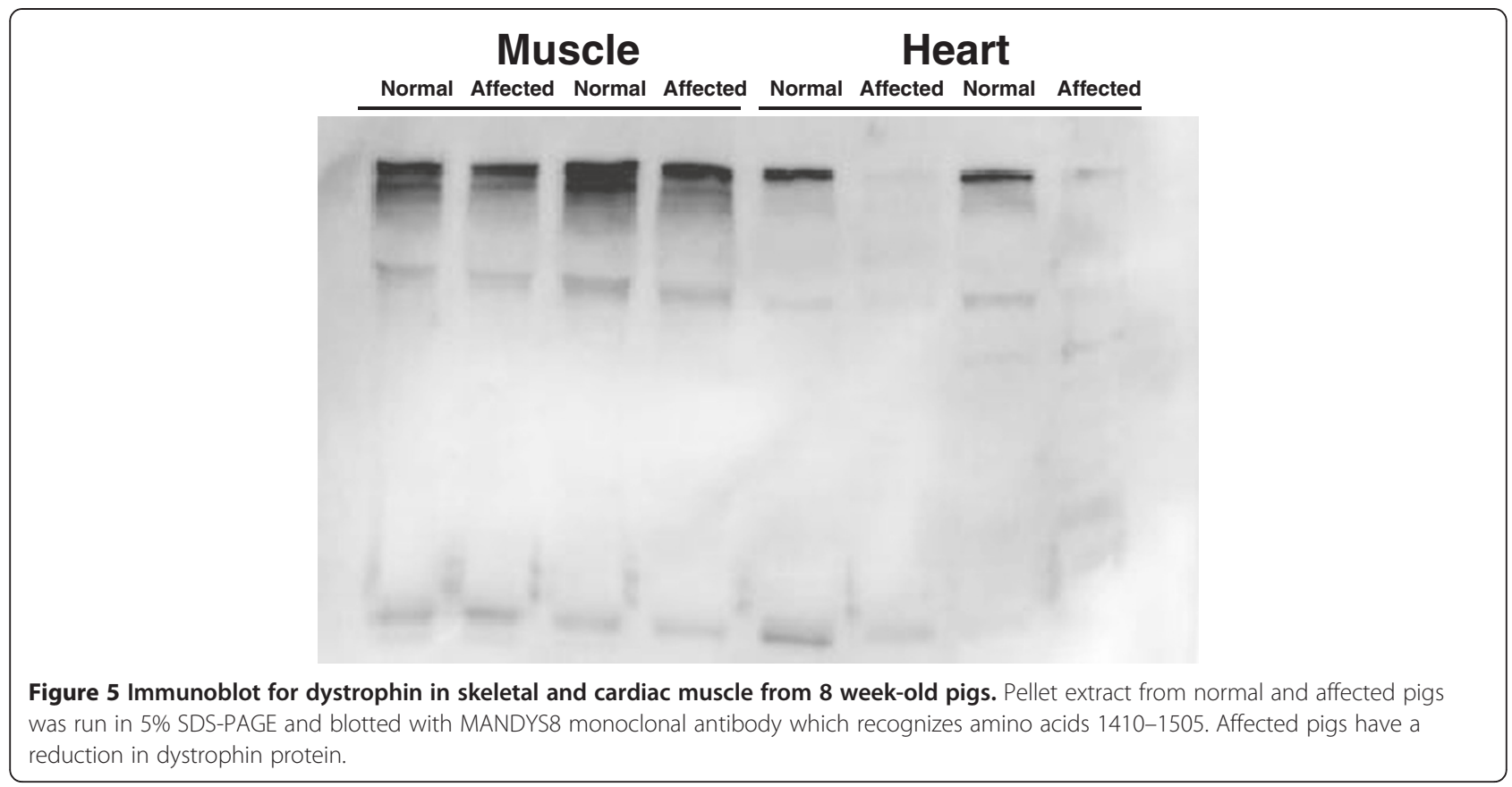

contraction. Cardiomyopathy that occurs without skeletal muscle involvement is frequently caused by missense mutations in the dystrophin gene [20]. Dystrophinopathies can also present with arrhythmia [22] or cardiorespiratory arrest after isoflurane anesthesia $[23,24]$. The pathophysiological reasons for anesthesia-induced cardiac arrest in patients with dystrophinopathies are unknown, however it is postulated that damaged, leaky muscle fibers (rhabdomyolysis) can lead to increased intracellular calcium and potassium released into the blood (hyperkalemia) and cardiac arrest $[21,24]$. It has

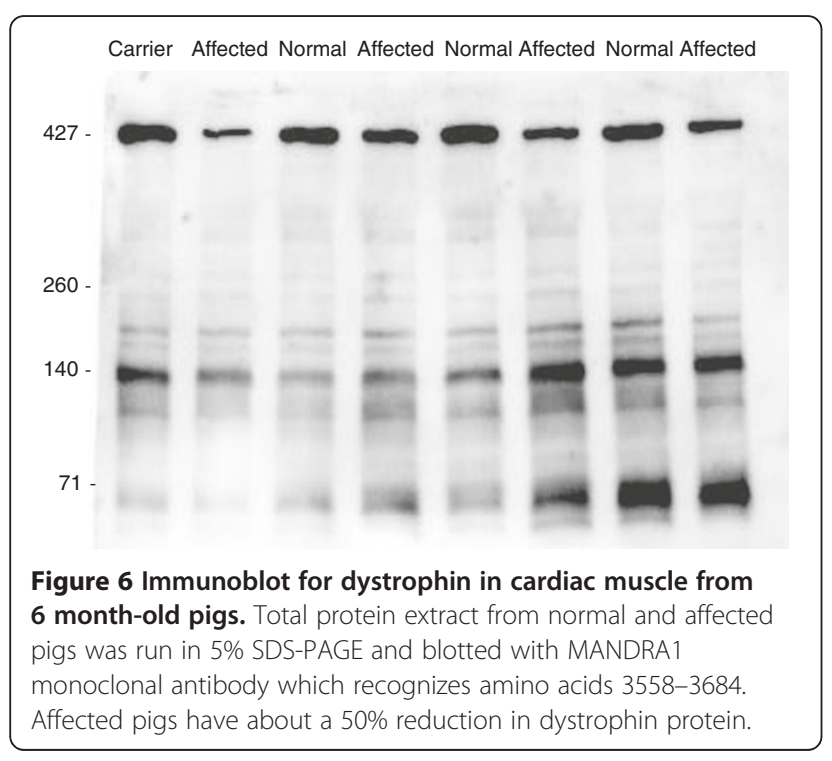

been reported that isoflurane anesthesia or stress induced rhabdomyolosis, hyperkalemia and death in dystrophindeficient cats [25]. This is the only report of stressinduced death in a dystrophic animal.

Dystrophin protein is usually absent by Western blot in DMD patients, while BMD patients usually have a decreased amount of normal or abnormal size protein [26], which is similar to the phenotype seen in the affected pigs. While it is not clear why missense mutations cause a reduction in dystrophin protein $[26,27]$ it may be due to damage of the protein by contractile stress.

One of the nonsynonymous SNPs, (85890_783; ss410758971), which causes an amino acid change of arginine to tryptophan at amino acid 1958, was the most significant marker for the stress response and could possibly be the causative mutation. The SNP is in exon 41 of dystrophin, which codes for spectrin repeat 15 of the central coiled-coil rod domain [28]. This basic repeat region is in the second actin-binding domain of dystrophin (ABD2) [29] and has also been shown to bind lipid [30]. Although in vitro mutation studies have not been reported for $\mathrm{ABD} 2$, missense mutations in actin-binding domain 1 (ABD1) can cause protein instability, misfolding and aggregation [31,32], leading to a reduction of expressed protein.

The variant $\mathrm{T}$ allele of 85890_783 (Trp) could be tracked to some of the founding sires and dams in the affected families. The frequency of this allele was higher than expected, based on the rate of spontaneous deaths of feeder-aged pigs in the population. Thus, if this is the 
causative mutation, the penetrance of this defect is not extremely high. Further studies are required to determine the causal genetic variation, the penetrance of this phenotype and if this locus accounts for losses during transportation of market weight animals.

\section{Conclusions}

Genetic mapping indicated the causative variation for a novel porcine stress syndrome is likely in the dystrophin gene. In addition to muscular dystrophies, mutations in human dystrophin can cause dilated cardiomyopathy, rhabdomyolosis and a malignant hyperthermia-like reaction in response to inhaled anesthesia, supporting the conclusion that this locus causes the observed phenotypes in pigs. The identification of the causative mutation in these families will allow investigation of the prevalence of this disease in commercial populations and its pleiotropic effects.

\section{Methods}

Animals

The animals were from a multigenerational LandraceDuroc-Yorkshire composite population developed at the U.S. Meat Animal Research Center (USMARC) by mating Yorkshire-Landrace composite females $(n=220)$ to either Duroc or Landrace boars selected from the industry ( $\mathrm{n}=12$ boars of each breed). This population was further developed by mating female descendants $(n=10$ / boar) to either a Duroc or Landrace-sired boar; Durocsired animals were mated to Landrace-sired animals and vice versa. Subsequent matings were random except that half-sib matings were avoided. The first affected animals identified were from the $7^{\text {th }}$ generation and the sire and dam were from the $6^{\text {th }}$ generation of this population. Litters were evaluated through generation 11. All animal procedures were reviewed and approved by the U.S. Meat Animal Research Center Animal Care and Use Committee and procedures for handling pigs complied with those specified in the Guide for the Care and Use of Agricultural Animals in Agricultural Research and Teaching [33].

\section{Identification of stress susceptible pigs}

We identified 2 barrows in the USMARC swine herd that died after a $1 \mathrm{~km}$ transport to a research location at 12 weeks of age. We reproduced the original mating along with sire-daughter matings to produce additional offspring. To induce a reproducible stress response, pigs were challenged with $3 \%$ isoflurane anesthesia for $3 \mathrm{~min}$ at 8 weeks of age. During the course of this study, pigs from other litters were identified from their reactions to regular processing, weighing or transport to the sale barn at 5-8 weeks of age. Their littermates were also challenged with anesthesia and additional affected animals were identified. A stress response was usually indicated when the pigs stopped breathing after 1-2 minutes of anesthetic, when they were slow to awaken after anesthesia, or displayed rigidity and blotching during handling. Matings were continued with these related offspring to produce additional animals. This produced a final population of 250 animals containing 49 affected pigs for genetic analysis.

\section{Sample collection and phenotyping}

Pigs were challenged at 8 weeks of age with isoflurane anesthesia (3\% for $3 \mathrm{~min}$ ) and body temperature, heart rate and ECG were monitored during anesthesia. During the 3 minute isoflurane challenge, ECG wave forms were obtained using a 3-wiring system recorded at $100 \mathrm{~Hz}$ using a 12-bit A/D. The signal was conditioned prior to recording using both a differential amplifier and a low pass filter to ensure proper signal. Blood was collected one week before challenge and immediately after isoflurane administration on most animals $(n=192)$. Blood was drawn into Li-heparin tubes for the measurement of creatine phosphokinase. Plasma creatine phosphokinase was measured using a 2-part reagent system (Pointe Scientific Inc., Canton, MI) in a SpectraMax M5 microplate plate reader (Molecular Devices, Sunnyvale, CA). Twenty-five $\mu \mathrm{l}$ samples were measured in duplicate and the rate of $\mathrm{NADH}$ formation was monitored at $340 \mathrm{~nm}$ and $37^{\circ} \mathrm{C}$. Samples that were greater than $2500 \mathrm{U} / \mathrm{L}$ were diluted in PBS and reassayed.

\section{Mapping the stress susceptible locus}

Initially, a pedigree of 58 pigs, including 15 affected animals, was genotyped with the Illumina PorcineSNP60 Beadchip containing 64,232 SNPs and for candidate gene SNP using the Sequenom MASSARRAY ${ }^{\circledR}$ system (Sequenom, San Diego, CA). Additional pigs were phenotyped as they were generated and subsequently genotyped. In total, 250 pigs, including 49 affected animals, their parents and unaffected siblings, were genotyped with the Illumina PorcineSNP60 Beadchip (Illumina, San Diego, CA) [34]. Genotyping of additional SNPs identified in the dystrophin gene and for candidate gene SNP was done using the Sequenom MASSARRAY ${ }^{\circledR}$ system (Sequenom, San Diego, CA). Multiplex assays with about $30 \mathrm{SNP} /$ group were designed using MASSARRAY ${ }^{\circledR}$ Assay Design software. Amplicon lengths were approximately $100 \mathrm{bp}$. Reaction conditions were performed as suggested by Sequenom iPLEX chemistry. Genome-wide associations were performed using the case-control option in PLINK [7].

\section{Sequencing}

Genomic DNA was extracted from blood buffy coats or from tails collected shortly after birth. Exons, flanking 
intronic regions and promoter regions of $D M D$ were amplified and sequenced from twelve animals with primers (Integrated DNA Technologies, Coralville, IA) designed using Primer 3 [35] in a Dyad DNA engine (Bio-Rad, Hercules, CA) using 0.5 U Hot Star Taq polymerase (Qiagen, Valencia, CA); 1x supplied buffer; $1.5 \mathrm{mM} \mathrm{MgCl} 2 ; 200 \mu \mathrm{M}$ dNTPs; $0.8 \mu \mathrm{M}$ each primer; and $100 \mathrm{ng}$ genomic DNA in $25 \mu \mathrm{l}$ reactions. The complete mRNA of the dystrophin muscle isoform was amplified and sequenced from cDNA using overlapping fragments and exon primers. Promoter regions were identified using Cister [36] and the cis-element matrices of TRANSFAC [37]. PCR reactions were treated with 0.1 $\mathrm{U}$ exonuclease (USB, Cleveland, $\mathrm{OH}$ ), and prepared for sequencing on an ABI3730 capillary sequencer (Applied Biosystems, Foster City, CA).

\section{Western immunoblotting of dystrophin}

Left ventricular and longissimus lumborum muscle samples from at least twelve affected and twelve agematched unaffected pigs were frozen in liquid nitrogen within 10 minutes of the time of death. Protein for Western blotting was extracted as reported before [38] with the addition of protease inhibitor cocktail (Sigma Chemical Co., St. Louis, MO). Dystrophin protein was detected using $15 \mu \mathrm{g}$ protein from cardiac and skeletal muscle run in $5 \%$ polyacrylamide gels using MANDYS8 and MANDRA1 anti-dystrophin monoclonal antibodies (Sigma Chemical Co., St. Louis, MO) diluted 1:400, goat anti-mouse IgG-HRP and SuperSignal ${ }^{\circledR}$ Western Blotting kit (Pierce, Rockford, IL). MANDYS8 recognizes residues 1431-1505 [39] and MANDRA1 recognizes residues 3667-3671 [40]. Equal loading of protein in the wells was confirmed by Coomassie Blue staining.

\section{Quantitative RT-PCR}

Total RNA was extracted from $50 \mathrm{mg}$ of porcine heart and longissimus lumborum muscle from 8-week old or 6-month old pigs by homogenization with TriZol reagent (Invitrogen, Carlsbad, CA) following the manufacturer's protocol. The RNA pellets were resuspended in $100 \mu \mathrm{L}$ DEPC treated water and absorbance was measured by spectrophotometry at $260 \mathrm{~nm}$. Total RNA $(2 \mu \mathrm{g})$ was reverse transcribed using oligo $\mathrm{dT}_{18}$ primer and M-MLV reverse transcriptase (Promega, Madison, WI). Primers for DMD (GenBank NM_001012408.1) and glyceraldehyde 3-phosphate dehydrogenase (GAPDH, GenBank AF017079) were designed for realtime RT-PCR using Primer 3. Primers used to amplify $D M D$ were located in exons 4 and 6. Dystrophin forward primer sequence (nucleotides 423 to 444) was $5^{\prime}$ tgcaggtcttgcagaaaaataa $-3^{\prime}$ and the reverse primer sequence was $5^{\prime}$ - gcaatccagccatgatattctt $-3^{\prime}$ (nucleotides 554 to 575). GAPDH forward primer sequence (nucleotides 739 to 757 ) was $5^{\prime}$-gcgtgaaccatgagaagtatga$3^{\prime}$ and the reverse primer sequence (nucleotides 947 to 967) was 5 '-ggtagaagcagggatgatgttc-3'. Real-time PCR was performed using $1 \mathrm{X} \mathrm{iQ}^{\mathrm{TM}} \mathrm{SYBR}^{\circledR}$ Green Supermix (Bio-Rad, Hercules, CA), 0.4 ng of cDNA and $0.3 \mu \mathrm{M}$ of each primer. The PCR reaction was performed at $95^{\circ} \mathrm{C}$ for $3 \mathrm{~min}$ followed by 40 cycles at $95^{\circ} \mathrm{C}$ for $20 \mathrm{~s}, 58^{\circ} \mathrm{C}$ for 30 s, and $70^{\circ} \mathrm{C}$ for $1 \mathrm{~s}$ on a MJ PTC-200 with a Chromo4 detector (MJ Research, Watertown, MA). A quantity of $0.4 \mathrm{ng}$ of cDNA was in the linear range of amplification and used for the real-time assays. The threshold cycle $(\mathrm{Ct})$ for $D M D$ and $G A P D H$ of each sample was determined and used to calculate the fold difference between samples ( $\mathrm{n}=12$ affected and 12 normal pigs) using the $2^{-\Delta \Delta C t}$ method [41].

\section{Additional files}

Additional files 1: Table S1. Human Malignant Hyperthermia Candidate Gene SNPs.

Additional files 2: Table S2. SNPs found in the Porcine DMD Gene.

\section{Competing interests}

The authors declare that they have no competing interests.

\section{Authors' contributions}

DJN and GAR designed challenge experiments, matings to generate animals, and genotyping data analysis. DJN performed biochemical experiments. TBB and SAJ were responsible for collecting physiological data and diagnosis and RTW provided bioinformatics. All authors read and approved the final manuscript.

\section{Acknowledgements}

The authors thank Sue Hauver, Dale Janssen, Karen Shuck and Kris Simmerman for technical assistance, Sherry Kluver for manuscript preparation and the National Swine Registry for providing samples for genotyping. USDA is an equal opportunity provider and employer. Mention of trade names or commercial products is solely for the purpose of providing information and does not imply recommendation, endorsement or exclusion of other suitable products by the U.S. Department of Agriculture.

Received: 22 September 2011 Accepted: 25 May 2012 Published: 12 June 2012

\section{References}

1. Ritter MJ, Ellis M, Berry NL, Curtis SE, Anil L, Berg E, Benjamin M, Butler D, Dewey C, Driessen B, DuBois P, Hill JD, Marchant-Forde JN, Matzat P, McGlone J, Mormede P, Moyer T, Pfalzgraf K, Salak-Johnson J, Siemens M, Sterle J, Stull C, Whiting T, Wolter B, Niekamp SR, Johnson AK: Review: Transport Losses in Market Weight Pigs: I. A Review of Definitions, Incidence, and Economic Impact. Prof Anim Sci 2009, 25:404-414.

2. Fujii J, Otsu K, Zorzato F, de Leon S, Khanna VK, Weiler JE, O'Brien PJ, MacLennan $\mathrm{DH}$ : Identification of a mutation in porcine ryanodine receptor associated with malignant hyperthermia. Science 1991, 253:448-451.

3. Ritter MJ, Ellis M, Hollis GR, McKeith FK, Orellana DG, Van Genugten P, Curtis SE, Schlipf JM: Frequency of the HAL-1843 mutation of the ryanodine receptor gene in dead and nonambulatory-noninjured pigs on arrival at the packing plant. J Anim Sci 2008, 86:511-514.

4. Murray AC, Johnson CP: Impact of the halothane gene on muscle quality and pre-slaughter deaths in Western Canadian pigs. Can J Anim Sci 1998, 78:543-548 
5. Allison $C P$, Johnson $R C$, Doumit ME: The effects of halothane sensitivity on carcass composition and meat quality in HAL-1843-normal pigs. J Anim Sci 2005, 83:671-678.

6. Allison CP, Marr AL, Berry NL, Anderson DB, Ivers DJ, Richardson LF Keffaber K, Johnson RC, Doumit ME: Effects of halothane sensitivity on mobility status and blood metabolites of HAL-1843-normal pigs after rigorous handling. J Anim Sci 2006, 84:1015-1021.

7. Purcell $S$, Neale B, Todd-Brown K, Thomas L, Ferreira MAR, Bender D, Maller J, Sklar P, de Bakker PIW, Daly MJ, Sham PC: PLINK: a toolset for whole-genome association and population-based linkage analysis. Am J Hum Genet 2007, 81:559-575.

8. Adzhubei IA, Schmidt S, Peshkin L, Ramensky VE, Gerasimova A, Bork P, Kondrashov AS, Sunyaev SR: A method and server for predicting damaging missense mutations. Nat Methods 2010, 7:248-249. http:// genetics.bwh.harvard.edu/pph2/.

9. Rohrer GA, Freking BA, Nonneman D: Single nucleotide polymorphisms for pig identification and parentage exclusion. Anim Genet 2007, 38:253-258.

10. Barrett JC, Fry B, Maller J, Daly MJ: Haploview: analysis and visualization of LD and haplotype maps. Bioinformatics 2005, 21:263-265.

11. Wedel DJ, Gammel SA, Milde JH, laizzo PA: Delayed onset of malignant hyperthermia induced by isoflurane and desflurane compared with halothane in susceptible swine. Anesthesiology 1993, 78:1138-1144.

12. Muntoni F, Torelli S, Ferlini A: Dystrophin and mutations: one gene, several proteins, multiple phenotypes. Lancet Neurol 2003, 2:731-740.

13. Flanigan KM, Dunn DM, von Niederhausern A, Soltanzadeh P, Gappmaier E, Howard MT, Sampson JB, Mendell JR, Wall C, King WM, Pestronk A, Florence JM, Connolly AM, Mathews KD, Stephan CM, Laubenthal KS, Wong BL, Morehart PJ, Meyer A, Finkel RS, Bonnemann CG, Medne L, Day JW, Dalton JC, Margolis MK, Hinton VJ, United Dystrophinopathy Project Consortium, Weiss RB: Mutational spectrum of DMD mutations in dystrophinopathy patients: application of modern diagnostic techniques to a large cohort. Hum Mutat 2009, 30:1657-1666.

14. Trimarco A, Torella A, Piluso G, Maria Ventriglia V, Politano L, Nigro V: Log-PCR: a new tool for immediate and cost-effective diagnosis of up to $85 \%$ of dystrophin gene mutations. Clin Chem 2008, 54:973-981.

15. Magri F, Del Bo R, D'Angelo MG, Govoni A, Ghezzi S, Gandossini S, Sciacco M, Ciscato P, Bordoni A, Tedeschi S, Fortunato F, Lucchini V, Cereda M, Corti S, Moggio M, Bresolin N, Comi GP: Clinical and molecular characterization of a cohort of patients with novel nucleotide alterations of the Dystrophin gene detected by direct sequencing. BMC Med Genet 2011, 12:37.

16. Magri F, Govoni A, D'Angelo MG, Del Bo R, Ghezzi S, Sandra G, Turconi AC, Sciacco M, Ciscato P, Bordoni A, Tedeschi S, Fortunato F, Lucchini V, Bonato S, Lamperti C, Coviello D, Torrente Y, Corti S, Moggio M, Bresolin N, Comi GP: Genotype and phenotype characterization in a large dystrophinopathic cohort with extended follow-up. J Neurol 2011, 258:1610-1653. in press.

17. Kirchmann C, Kececioglu D, Korinthenberg R, Dittrich S: Echocardiographic and electrocardiographic findings of cardiomyopathy in Duchenne and Becker-Kiener muscular dystrophies. Pediatr Cardiol 2005, 26:66-72.

18. Cohen N, Muntoni F: Multiple pathogenetic mechanisms in X linked dilated cardiomyopathy. Heart 2004, 90:835-841.

19. Arbustini E, Diegoli M, Morbini P, Dal Bello B, Banchieri N, Pilotto A, Magani F, Grasso M, Narula J, Gavazzi A, Viganò M, Tavazzi L: Prevalence and characteristics of dystrophin defects in adult male patients with dilated cardiomyopathy. J Am Coll Cardiol 2000, 35:1760-1768.

20. Feng J, Yan J, Buzin CH, Towbin JA, Sommer SS: Mutations in the dystrophin gene are associated with sporadic dilated cardiomyopathy. Mol Genet Metab 2002, 77:119-126.

21. Allen DG, Whitehead NP: Duchenne muscular dystrophy-what causes the increased membrane permeability in skeletal muscle? Int J Biochem Cell Biol 2011, 43:290-294.

22. Wakefield SE, Dimberg EL, Moore SA, Tseng BS: Dystrophinopathy presenting with arrhythmia in an asymptomatic 34-year-old man: a case report. J Med Case Reports 2009, 3:8625.

23. Girshin M, Mukherjee J, Clowney R, Singer LP, Wasnick J: The postoperative cardiovascular arrest of a 5-year-old male: an initial presentation of Duchenne's muscular dystrophy. Paediatr Anaesth 2006, 16:170-173.

24. Poole TC, Lim TY, Buck J, Kong AS: Perioperative cardiac arrest in a patient with previously undiagnosed Becker's muscular dystrophy after isoflurane anaesthesia for elective surgery. Br J Anaesth 2010, 104:487-489.

25. Gaschen F, Gaschen L, Seiler G, Welle M, Jaunin VB, Jmaa DG, Neiger-Aeschbacher G, Adé-Damilano M: Lethal peracute rhabdomyolysis associated with stress and general anesthesia in three dystrophin-deficient cats. Vet Pathol 1998, 35:117-123.

26. Deburgrave N, Daoud F, Llense S, Barbot JC, Récan D, Peccate C Burghes AH, Béroud C, Garcia L, Kaplan JC, Chelly J, Leturcq F: Protein- and mRNA-based phenotype-genotype correlations in DMD/BMD with point mutations and molecular basis for BMD with nonsense and frameshift mutations in the DMD gene. Hum Mutat 2007, 28:183-195.

27. Lenk U, Oexle K, Voit T, Ancker U, Hellner KA, Speer A, Hübner C: A cysteine 3340 substitution in the dystroglycan-binding domain of dystrophin associated with Duchenne muscular dystrophy, mental retardation and absence of the ERG b-wave. Hum Mol Genet 1996, 5:973-975.

28. Le Rumeur E, Winder SJ, Hubert JF: Dystrophin: more than just the sum of its parts. Biochim Biophys Acta 2010, 1804:1713-1722.

29. Amann KJ, Guo AW, Ervasti JM: Utrophin lacks the rod domain actin binding activity of dystrophin. J Biol Chem 1999, 274:35375-35380.

30. Legardinier S, Raguénès-Nicol C, Tascon C, Rocher C, Hardy S, Hubert JF, Le Rumeur E: Mapping of the lipid-binding and stability properties of the central rod domain of human dystrophin. J Mol Biol 2009, 389:546-558.

31. Henderson DM, Lee A, Ervasti JM: Disease-causing missense mutations in actin binding domain 1 of dystrophin induce thermodynamic instability and protein aggregation. Proc Natl Acad Sci USA 2010, 107:9632-9637.

32. Singh SM, Kongari N, Cabello-Villegas J, Mallela KM: Missense mutations in dystrophin that trigger muscular dystrophy decrease protein stability and lead to cross-beta aggregates. Proc Natl Acad Sci USA 2010, 107:15069-15074.

33. FASS: Guide for Care and Use of Agricultural Animals in Agricultural Research and Teaching. 3rd edition. Savoy, IL: Fed. Animal Science Society; 2010.

34. Ramos AM, Crooijmans RP, Affara NA, Amaral AJ, Archibald AL, Beever JE, Bendixen C, Churcher C, Clark R, Dehais P, Hansen MS, Hedegaard J, Hu ZL, Kerstens HH, Law AS, Megens HJ, Milan D, Nonneman DJ, Rohrer GA, Rothschild MF, Smith TP, Schnabel RD, Van Tassell CP, Taylor JF, Wiedmann RT, Schook LB, Groenen MA: Design of a high density SNP genotyping assay in the pig using SNPs identified and characterized by next generation sequencing technology. PLoS One 2009, 4:e6524.

35. Rozen S, Skaletsky HJ: Primer3 on the WWW for general users and for biologist programmers. In Bioinformatics Methods and Protocols. Edited by Krawetz S, Misener S. Totowa, NJ: Humana Press; Methods Mol Biol; 2000:365-386.

36. Frith MC, Hansen U, Weng Z: Detection of cis-element clusters in higher eukaryotic DNA. Bioinformatics 2001, 17:878-889.

37. Wingender E, Chen X, Hehl R, Karas H, Liebich I, Matys V, Meinhardt T, Pruss M, Reuter I, Schacherer F: TRANSFAC: an integrated system for gene expression regulation. Nucleic Acids Res 2000, 28:316-319.

38. Geesink GH, Koohmaraie M: Postmortem proteolysis and calpain/ calpastatinactivity in callipyge and normal lamb biceps femoris during extended postmortem storage. J Anim Sci 1999, 77:1490-1501.

39. Sedgwick SG, Nguyen TM, Ellis JM, Crowne H, Morris GE: Rapid mapping by transposon mutagenesis of epitopes on the muscular dystrophy protein, dystrophin. Nucleic Acids Res 1991, 19:5889-5894.

40. Morris GE, Simmons C, Man NT: Apo-Dystrophins (dp140 and dp71) and dystrophin-splicing isoforms in developing brain. Biochem Biophys Res Comm 1995, 215:361-367.

41. Livak KJ, Schmittgen TD: Analysis of relative gene expression data using real-time quantitative PCR and the 2- $\Delta \Delta C T$ Method. Methods 2001, 25:402-408

doi:10.1186/1471-2164-13-233

Cite this article as: Nonneman et al:: A defect in dystrophin causes a novel porcine stress syndrome. BMC Genomics 